\title{
Sexual behaviour of women attending an inner-city STD clinic before and after a general campaign for safer sex in Denmark
}

Frederik de Fine Olivarius, Anne-Marie Worm, Carsten Sand Petersen, Susanne Kroon, Elsebeth Lynge

\begin{abstract}
Objectives-To examine the sexual behaviour and the prevalence of sexually transmitted diseases (STD) among females attending an inner-city STD clinic before and after safer sex campaigns.

Subjects-In 1984981 women and in 1988 684 women were interviewed immediately after the venerological examination. Setting-Department of Dermato-Venereology, Bispebjerg Hospital, Copenhagen, Denmark.

Methods-In a face to face interview, details of symptoms, age at coitarche, number of sexual partners (lifetime and during the last year), obstetric history, and contraceptive methods were recorded.

Results-A substantially higher proportion of women used condoms in 1988 than in 1984. A dramatic decrease in the prevalence of gonorrhoea occurred (from $22 \%$ in 1984 to $6 \%$ in $1988, p<0.01$ ), whereas an increase in the number of patients with genital warts was observed (from $4 \%$ in 1984 to $10 \%$ in $1988, p<0.05$ ). The prevalence of chlamydia, genital herpes, and cervical dysplasia remained unchanged. No significant changes in the number of sexual partners, or the frequency of sexual intercourse or unplanned pregnancy could be detected from 1984 to 1988 .

Conclusions-The safer sex campaigns have only been partly succesful, as a general reduction in all sexually transmitted diseases should be expected as a result of the increased use of condoms. Future campaigns should focus on the correct use of condoms, and encourage a lifestyle with stable sexual relationship.
\end{abstract}

Department of Dermato-Venereology, Bispebjerg Hospital $\mathrm{F}$ de $\mathrm{F}$ Olivarius A-M Worm C S Petersen $S$ Kroon

Danish Cancer Society, Danish Cancer Registry E Lynge

Address correspondence to: Frederik de Fine Olivarius, MD, Department of Dermatology, Gentofte Hospital, DK-2900 Hellerup, Denmark Accepted for publication 18 May 1992

\section{Introduction}

Since 1985, the Danish health authorities have given high priority to educational campaigns for prevention of HIV infection in the general population. However, little is known about the effects of these campaigns advocating safer sex. DeBuono et al found limited changes between 1975 and 1988 in the sexual practices of college women attending a large private university in northeast USA, apart from an increase in the use of condoms. ${ }^{1}$ Similar trends were observed among female patients seeking a sexually transmitted disease (STD) clinic in England. $^{2}$ Unlike the beneficial result of behavioural changes on the STD rates among homosexual males, ${ }^{34}$ STD rates have not decreased to the same degree in the heterosexual population. ${ }^{56}$

Patients who seek care at inner-city STD clinics tend to be relatively young, and at risk for a number of reproductive health care problems, such as sexually transmitted diseases, pelvic inflammatory diseases, unplanned pregnancies, and cervical dysplasia. ${ }^{78}$ These problems are related to high risk behaviour, including unprotected intercourse and multiple sexual partners. 'Thus, inner-city STD clinics may provide an important access point for evaluation of the effect of public health messages that recommend increased use of barrier methods of contraception and limited number of sexual partners, in order to restrict the spread of sexually transmitted diseases including HIV.

Our study began in 1984 with the aim of assessing female sexual behaviour over time. The first observations and a brief discussion of the implications are presented.

\section{Patients and methods}

Consecutive Danish speaking female patients attending the Copenhagen Venereal Disease Clinic in an 8 month period in 1984 and a 7 months period in 1988 were offered a face to face interview on sexual behaviour with one of the contact tracers working in the clinic. Due to difficulties in obtaining ethical committee approval for patients below the age of 18 without their parents approval, only patients aged 18 years or over were included. The interview, based on a questionnaire, was carried out immediately after the venereological examination. Details of symptoms, age at coitarche, number of sexual partners, number of weekly sexual intercourses during the last 3 months, and contraceptive methods were recorded on a standardised schedule, and supplied with the result of the venereological examination.

For statistical analyses, the Chi square method was used; a $p$ value of $<0.05$ was considered significant.

\section{Results}

In the study periods in 1984 and 1988 a total number of 1481 and 1148 women attended the clinic of whom 1269 and 1096, respectively, were aged 18 years or more. In 1984981 $(77 \%)$ of 1269 and in $1988684(62 \%)$ of 1096 women completed the interview. The mean age was $24 \cdot 2$ years (range 18-60) in 1984 and 26.6 years (range 18-79) in 1988. In 1984212 
Table 1 Sexually transmitted diseases diagnosed in female patients attending an STD clinic in Copenhagen in 1984 $(n=1269)$ and $1988(n=1096)$. (Percentages in brackets).

\begin{tabular}{lcc}
\hline & 1984 & 1988 \\
\hline Chlamydia & $324 / 1246(26)$ & $208 / 841(25)$ \\
Gonorrhoea & $278 / 1264(22)$ & $49 / 843(6) \dagger$ \\
Genital warts & $47 / 1252(4)$ & $88 / 868(10)^{\star}$ \\
Herpes genitalis & $76 / 1269(6)$ & $33 / 867(4)$ \\
Cervical dysplasia & $74 / 1066(7)$ & $33 / 613(5)$ \\
\hline$\star_{p}<0.05$ & & \\
$t p<0.01$ & &
\end{tabular}

women (14\%) were below 18 years of age, compared with 52 women $(4.5 \%)$ in 1988 .

The main reasons for attending the clinic were recorded in all women who were eligible. Significantly fewer women presented with discharge in 1988, 233 of $1096(21 \%)$ versus 333 of $1269(26 \%)$ than in $1984(p<0.05)$, and a much lower rate of women were known contacts to partner(s) with gonorrhoea in 1988, 65 of $1096(6 \%)$ versus 365 of $1269(29 \%)$, than in $1984(p<0.05)$. In 1988 a significantly higher rate of patients presented with suspected wart virus infection, 62 of $1096(6 \%)$ versus 23 of $1269(2 \%)$, than in 1984 , $(p<0.05)$. Approximately one third of the patients attended the clinic in 1988 mainly for an HIV antibody testing, whereas this test was not available in 1984 .

The STD prevalences in the female population in 1984 and 1988 are shown in table 1. The number of females with gonorrhoea decreased $(p<0.01)$, whereas the number of female patients with genital warts increased $(p<0.05)$ from 1984 to 1988 (table 1). The prevalence of chlamydia, genital herpes, or cervical dysplasia was unchanged (table 1). Syphilis was diagnosed in only two women, one in 1984 and one in 1988. The number of women with trichomoniasis was very low in both study periods, and only found in three $(0.6 \%)$ of 508 women examined in 1988.

In both study periods the STD prevalences in the interviewed group did not differ from the prevalences in the total group of eligible patients.

\section{Interviews}

The lifetime number of sexual partners and the number of partners the previous year are shown in table 2. Whereas no major changes are detectable in the total number of sexual partners from 1984 to 1988 , there seems to be a trend towards fewer females with more than 10 sexual partners during the last year in 1988 (table 2).

The frequency of intercourse on a weekly

Table 2 Number of sexual partners during lifetime and during last twelve months in female STD patients in $1984(n=981)$ and $1988(n=684)$. (Percentages in brackets).

\begin{tabular}{rrrrrr}
\hline & \multicolumn{2}{l}{ Lifetime sexual partmers } & & \multicolumn{2}{l}{ Last year sexual partners } \\
\cline { 2 - 3 } \cline { 5 - 6 } No of partmers & 1984 & 1988 & & 1984 & 1988 \\
\hline 1 & $4 / 978(0)$ & $4 / 678(0)$ & & $163 / 979(17)$ & $140 / 677(21)$ \\
$2-5$ & $110 / 978(11)$ & $63 / 678(9)$ & & $570 / 979(58)$ & $414 / 677(61)$ \\
$6-10$ & $181 / 978(19)$ & $129 / 678(19)$ & & $154 / 979(16)$ & $99 / 677(15)$ \\
$11-20$ & $285 / 978(29)$ & $202 / 678(30)$ & & $56 / 979(6)$ & $14 / 677(2)$ \\
$21-50$ & $269 / 978(28)$ & $191 / 678(28)$ & & $21 / 979(2)$ & $5 / 677(1)$ \\
$51-100$ & $71 / 978(7)$ & $58 / 678(9)$ & & $4 / 979(0)$ & $2 / 677(0)$ \\
$>100$ & $58 / 978(6)$ & $31 / 678(5)$ & & $10 / 979(1)$ & $0 / 677(0)$ \\
\hline
\end{tabular}

Table 3 Frequency of weekly intercourse during the last 3 months among female patients in $1984(n=981)$ and in $1988(n=684)$. (Percentages in brackets).

\begin{tabular}{llr}
\hline Frequency & 1984 & 1988 \\
\hline $0-1$ & $359 / 977(37)$ & $258 / 679(38)$ \\
$1-2$ & $180 / 977(19)$ & $91 / 679(13)$ \\
$2-3$ & $208 / 977(21)$ & $135 / 679(20)$ \\
$4-5$ & $130 / 977(13)$ & $108 / 679(16)$ \\
$5-10$ & $77 / 977(8)$ & $67 / 679(10)$ \\
$>10$ & $22 / 977(2)$ & $20 / 679(3)$ \\
\hline
\end{tabular}

basis during the last 3 months was the same in 1984 as in 1988 (table 3). The mean age at coitarche was 15.7 years in 1984 compared with 15.4 years in 1988 . The mean age at coitarche was independant of the age of the woman at the time of the interview.

In $198476 \%(745 / 981)$ had previously been examined for STD, compared with $74 \%$ $(505 / 683)$ in 1988. A previous history of chlamydia, gonorrhoea, genital warts, and genital herpes was mentioned by $82 / 981(8 \%)$, $310 / 981(32 \%), 119 / 981(12 \%)$, and $48 / 981$ $(5 \%)$ respectively in 1984 , and by $159 / 684$ (23\%), 146/684 (21\%), 116/684 (17\%), and $50 / 684(7 \%)$ respectively in 1988 . The number of women reported to have had chlamydia was significantly higher in $1988(\mathrm{p}<0.01)$, whereas the number of women reported to have had gonorrhoea was lower $(p<0.01)$. A history of genital warts was more common in 1988 than in $1984(\mathrm{p}<0.05)$.

The contraceptive methods used by the female population in 1984 and 1988 are shown in table 4. Owing to differencies in the questionnaire these figures cannot be directly compared, as the question in 1984 asked for the predominant method used for contraception, whereas the question in 1988 asked whether one or more of these methods were used for contraception. However, the number of women using oral contraception or IUD as contraception decreased from 1984 to 1988 .

In 1984 only $11 \%(110 / 981)$ of the women used the condom as the major contraceptive method. In $198851 \%$ (344/679) of the women used condoms as one of the contraceptive methods of whom $24 \%$ (83/344) stated always to use condoms and the other $76 \%(261 / 344)$ to use it irregularly. Of the condom users in $198882 \%$ (283/344), stated that they were using condoms more frequently than one year before. In 1988, the frequency of women stating that they never used condoms increased with age, whereas this trend could not be demonstrated in 1984 . In 1988 the prevalence of chlamydia was $24 \%(59 / 246)$ among women who never used condoms, and $26 \%(71 / 271)$

Table 4 Contraceptive methods among females attending an STD clinic in Copenhagen in $1984(n=981)$ and in $1988(n=684)$. (Percentages in brackets).

\begin{tabular}{lcc}
\hline & $1984^{*}$ & $1988 t$ \\
\hline Oral & $310 / 981(32)$ & $184 / 679(27)$ \\
IUD & $271 / 981(28)$ & $146 / 679(21)$ \\
Diaphragm & $53 / 981(5)$ & $48 / 679(7)$ \\
Condom & $110 / 981(11)$ & $334 / 679(51)$ \\
Other & $71 / 981(7)$ & $34 / 679(5)$ \\
None & $166 / 981(17)$ & $120 / 679(18)$ \\
\hline
\end{tabular}

The predominant method used is given.

tThe method is given if used. 
Table 5 Number of pregnancies, deliveries, and abortions among female patients attending an STD clinic in Copenhagen in $1984(n=981)$ and $1988(n=684)$. (Percentages in brackets).

\begin{tabular}{lcc}
\hline & 1984 & 1988 \\
\hline $\begin{array}{l}\text { One or more prior } \\
\text { pregnancy }\end{array}$ & $497 / 980(51)$ & $321 / 679(47)$ \\
$\begin{array}{l}\text { One or more prior } \\
\text { delivery }\end{array}$ & $233 / 980(24)$ & $123 / 679(18) \dagger$ \\
$\begin{array}{l}\text { One or more prior } \\
\text { miscarriage }\end{array}$ & $93 / 980(9)$ & $67 / 679(10)$ \\
$\begin{array}{l}\text { One or more prior } \\
\text { provoked abortion }\end{array}$ & $368 / 980(38)$ & $232 / 679(34)$ \\
\hline tp $<0.05$ & &
\end{tabular}

among women, who stated that they always or sometimes used condoms.

The number of pregnancies, deliveries, and abortions are listed in table 5. No significant changes could be detected from 1984 to 1988 , except for a slight decrease in the number of prior deliveries in $1988(p<0.05)$.

\section{Discussion}

In $198477 \%$ of women aged 18 years or more were interviewed, compared with $62 \%$ in 1988. This decrease was not due to patient refusal but to lack of time, as fewer contact tracers were working at the clinic in 1988 . A high number of women attended the clinic for HIV-testing only in 1988, which explains the lower rate of venereological examinations carried out in 1988 compared with 1984, when HIV-testing was not performed routinely. The increase in mean age from $24 \cdot 2$ to $26 \cdot 2$ years can at least partly be explained by the fact that women attending for HIV-testing only were older than women attending for an STD examination. Though not completely comparable due to differencies in the question about contraception there is no doubt that the number of condom using women increased substantially from 1984 to 1988 , which is also supported by the fact that $82 \%$ in 1988 stated that they used condoms more frequently than one year before the interview. Our study is therefore in agreement with a recent report, ${ }^{2}$ demonstrating an increased use of condoms in female patients attending an inner-city STD clinic in London. In the latter study the use of condoms among heterosexual women increased from $24 \%$ in 1987 to $48 \%$ in $1989 .{ }^{2}$ Other studies from STD clinics have, however, shown much lower rates of condom use. ${ }^{7-11}$

From 1984 to 1988 a dramatic decrease in the number of women who were contacts to partners with gonorrhoea, and women with a diagnosis of gonorrhoea occurred. Surprisingly, we were not able to detect a decrease in the rate of other sexually transmitted diseases, such as chlamydia and genital herpes, and the prevalence of genital warts increased.

We would have expected that the prevalence of chlamydial infections amongst women using condoms would be lower than among women who never used condoms. However, although the number of women using condoms increased substantially from 1984 to 1988 , only $24 \%$ of the condom using women in 1988 used it consistently. The lack of protection by condoms may therefore mainly be explained by inconsistent use. Condom failure, including splitting, slipping of the penis during intercourse, and inadvertent genital contact before use could however also contribute to this finding. There seems therefore to be a great need for more detailed information about the correct use of condoms. Combination of spermicidal creams or gels and condoms may also be a way of reducing the risk of acquiring an infection during intercourse.

The observation that a significantly higher proportion of the women in 1988 had a previous diagnosis of chlamydia may be due to increased screening during the years between the study periods, and may therefore not reflect an increase in sexual activity among the women attending the STD clinic. The procedure in diagnosing genital warts has not been changed between the study periods and the increasing number of patients with genital warts could therefore reflect a general increase of this infection among younger women.

We have no explanation of the nearly total disappearence of trichomoniasis in our female study populations. The decrease of this infection seens to have taken place before the AIDS campaigns in Danmark.

The information campaigns emphasising fear of AIDS clearly did not stop the women from having sexual activity. However, in 1988 only $4.5 \%$ of the women attending the clinic were below 18 years of age, compared with $14 \%$ in 1984 . We do not know if this is due to an effect of the campaigns on the youngest group of sexually active women. Our study populations were highly sexual active both in 1984 and 1988, with multiple sexual partners and a high frequency of intercourse. Future general sex education programmes should encourage a lifestyle with more stable sexual relationships aiming at reducing the number of sexual partners.

The lack of decrease from 1984 to 1988 in the high rate of unplanned pregnancies found in our study, may partly be explained by incorrect or inconsistent use of condoms, together with the fact, that fewer women used oral contraception and IUD in 1988. In Denmark, the number of legal abortions has been unchanged from 1984 to 1988 , with 16.4 abortions per 1000 fertile women in both years. ${ }^{12}$ Further educational efforts are needed in order to diminish the problem of unplanned pregnancy. Concomitant use of barrier contraception and oral contraception or IUD may be a way to reduce this problem.

It will be important to repeat the study to see if further changes have occurred in female sexual behaviour since 1988 .

1 DeBuono BA, Zimmer SH, Daamen M, McCormack WM Sexual behaviour of college women in 1975, 1986 and Sexual behaviour of college women in 1975, 1986 and

Evans BA, McCormack SM, Bond RA, MacRae KD. Trends in sexual behaviour and HIV testing among women presenting at a genitourinary medicine clinic during the advent of AIDS. Genitourin Med 1991;67: 194-8.

3 Carne CA. Weller IV, Johnson G, et al. Prevalence of antibody to human immunodeficiency virus, gonorrhoea rates and changed sexual behaviour in homosexual men in London. Lancet 1987;i:656-8. 
4 Poulsen A, Ullman S. AIDS-induced decline of syphilis in Denmark. Acta Derm Venereol 1985;65:567-9.

5 Rice RJ, Aral SO, Blount JH, Zaidi AA. Gonorrhoea in the United States 1975-1984: Is the giant only sleeping? Sex Trans Dis 1987;14:83-7.

6 Centers for Disease Control. Increases in primary and secondary syphilis-United States. MMWR 1987;36: 393-6.
3econdary syphilis-United States. $M M W R$ 1987,36:

Upchurch DM, Farmer MY, Glasser D, Hook EW, III. Contraception needs and practices among women attending an inner-city STD clinic. Am f Pub Health 1987;

8 Quinn TC, Glasser D, Caunon RO, et al. Human immunodeficiency virus infection among patients attending clinics for sexually transmitted diseases. N Engl f Med 1988; 318:197-203.

9 Sonnex C, Hart GJ, Williams P, Adler MW. Condom use by heterosexuals attending a department of GUM: attitudes and behaviour in the light of HIV infection. Genitourin Med 1989;65:248-51.

10 Thin RN, Whatley JD, Blackwell AL. STD and contraception in adolescents. Genitourin Med 1989;65:157-60.

11 Opaneye AA, Willmott C. The role of genitourinary medicine in adolescent sexuaility. Genitourin Med 1991; 67:44-6.

12 Statistik om prevention og aborter. The Danish National Board of Health 1989 